Article

\title{
Solar Air Collectors for Space Heating and Ventilation Applications-Performance and Case Studies under Romanian Climatic Conditions ${ }^{\dagger}$
}

\section{Sanda Budea}

Hydraulics, Hydraulic Machinery and Environmental Engineering Department, Power Engineering Faculty, University Politechnica of Bucharest, 313 Spl. Independentei, District 6, Bucharest 060042, Romania; E-Mail: s_budea@yahoo.com; Tel.: +40-021-402-9296; Fax: +40-021-402-9865

$\dagger$ This paper was previously presented at the 1st International e-Conference on Energies 2014, c016, doi:10.3390/ece-1-c016, available online: http://www.sciforum.net/conference/ece-1/paper/2344.

Received: 9 April 2014; in revised form: 12 June 2014 / Accepted: 13 June 2014 /

Published: 18 June 2014

\begin{abstract}
Solar air collectors have various applications: on the one hand, they can be used for air heating in cold seasons; on the other hand they can be used in summer to evacuate the warm and polluted air from residential, offices, industrial, and commercial buildings. The paper presents experimental results of a solar collector air, under the climatic conditions of the Southeastern Europe. The relationships between the direct solar irradiation, the resulting heat flow, the air velocity at the outlet, the air flow rate, the nominal regime of the collector and the efficiency of conversion of solar energy into thermal energy are all highlighted. Thus, it was shown that after a maximum $50 \mathrm{~min}$, solar air collectors, with baffles and double air passage can reach over $50 \%$ efficiency for solar irradiation of $900-1000 \mathrm{~W} / \mathrm{m}^{2}$. The article also presents a mathematical model and the results of a computational program that allows sizing solar collectors for the transfer of air, with the purpose of improving the natural ventilation of buildings. The article is completed with case studies, sizing the area to be covered with solar collectors, to ensure ventilation of a house with two floors or for an office building. In addition, the $A C H$ (air change per hour) coefficient was calculated and compared.
\end{abstract}

Keywords: solar air collector; performances; space heating; cooling; case studies 


\section{Introduction}

In the context that solar energy, as a renewable source of energy, is used in very small proportion (only $2 \%$ ), specialists' research must focus on improving the operating efficiency of solar heat collectors and extending their domains of applications. This paper analyzes the efficiency of the conversion of solar energy into heat in solar air collectors. Collectors' performances depend on the collectors' materials [1,2] and the technology used in the manufacturing of the collector (form of flow channels with baffles, roughness, and induced air movement turbulence) [3-6]. Solar collectors' performance depends, also, on their operating parameters: the global solar irradiance, air-flow velocity and air-flow rate discharged through the solar collector, and operating time. The improvement in the energy performance of solar heat collectors is important, both for their use in space heating, and also in natural ventilation systems integrated in the technology of building passive houses $[7,8]$. Thus, there are two technologies to consider regarding solar air collectors: in a closed loop system, when the air is circulated from the house to the collector and back to the house-for heating; and in an open loop system, when the air is taken from outside, flows through the panel, is circulated into the building, and goes back outside - for ventilation, to improve indoor air quality [9].

In this regard, this article shows, on the one hand, the performance of solar air collectors used under the climatic conditions of Bucharest (Romania) during the cold season, to establish their performance in the heating process, and, on the other hand, during the warm season, to establish their efficiency in improving the ventilation process.

In our experimental analysis, the heat flow provided by a SH $1500 \mathrm{G}$ solar collector (Your Solar Home Inc., Aurora, ON, Canada) and performances depending on solar radiation and operating time were followed. Thus, conclusions about the optimal working point of this solar collector were highlighted, in the heating and cooling processes. Experimental research demonstrated that an efficiency of about $50 \%$ can be achieved for a radiation of $900-1000 \mathrm{~W} / \mathrm{m}^{2}$. Optimal operating regime is achieved after about 50-55 min. The relationships between air-velocity at the outlet of the solar collector, the incident radiation, and air temperature variation between entering and leaving of the collector were determined. The greater the temperature difference, the greater the conversion efficiency, as shown in [10,11].

This article presents a computational model for the ventilation of living spaces with solar panels, in order to determine the surface to be covered with solar air collectors, with different solar radiation assumptions, correlated with the air velocity in the panel and the variation of the temperature supposed to be achieved. This model was applied in two case studies: for a house with about $200 \mathrm{~m}^{3}$ of living space, and for an office building with about $1000 \mathrm{~m}^{3}$ of workspace. The numerical application can easily be used for sizing solar panels for the ventilation of residential, commercial, or industrial areas.

\section{Experimental Research}

\subsection{Characteristics of the Solar Air Collector}

In our experimental research, a commercial solar collector, $\mathrm{SH} 1500 \mathrm{G}$, was used, glazed to reduce the losses by radiation and convection, and thermally insulated to avoid heat dissipation. This type of collector is a double pass with baffles to create flow turbulence and to increase the absorber surface; 
the same technology is also used in [12,13]. The casing and the absorber material are extruded aluminum. The collector has, on the upper side, a $14 \mathrm{~W}$ photovoltaic panel to deliver energy to the small, variable speed axial fan placed on the upper back side, to hasten the exit of warm air. The air collector's surface is $1.9 \mathrm{~m}^{2}$, and $0.5 \mathrm{~m}^{2}$ for the photovoltaic panel. The air enters at the bottom of the panel and exits through the upper side via ducts with a diameter of $127 \mathrm{~mm}$. The unit can be controlled from a thermostat. The operation of a solar collector can be done with optimal control of parameters in order to maximize the energy, and ensure thermal comfort, by stopping the system from overheating.

\subsection{Test Setup}

Romania's geographical location, taking, as reference, the city of Bucharest, located at $44^{\circ} 25^{\prime}$ North latitude and $25^{\circ} 6^{\prime}$ East longitude, was taken into account in establishing the incident solar global radiation, at an angle of $50^{\circ}$ for the winter months, and $35^{\circ}$ for the summer months. Firstly, a proprietary software to establish the radiation on a tilted surface, was used to set $I_{g}$, based on time and atmospheric temperature, $T_{a}$. Temperature and radiation are variable over time, and they were obtained from measured values every 10 min for January and July. Values are shown in Figures 1a and 2a, and they were compared with the values determined by the application JRC PVGIS [14], pictured in Figures $1 \mathrm{~b}$ and $2 \mathrm{~b} . I_{\mathrm{g}}$ and $T_{\mathrm{a}}$ are interpolated values with sixth degree polynomials. $I_{\mathrm{g}}$ from Figure 1a,b have similar values in January. $I_{\mathrm{g}}$ from Figure $2 \mathrm{a}, \mathrm{b}$ are between 800 and $1100 \mathrm{~W} / \mathrm{m}^{2}$ in July, for the time intervals of 10-15.

The SH 1500G solar collector, see Figure 3a, was tested in the Polytechnic University of Bucharest, in the Hydraulic Laboratory. The experimental stand is mobile, and has the ability to modify the inclination angle of the panel, as shown in the chart in Figure $3 \mathrm{~b}$.

Figure 1. Global solar irradiance on a tilted plane for a clean sky day from January 2009:

(a) Proprietery software, $T^{\prime}$ a and $I_{\mathrm{g}}$ are interpolated values with sixth degree polynomials;

(b) JRC PVGIS application.

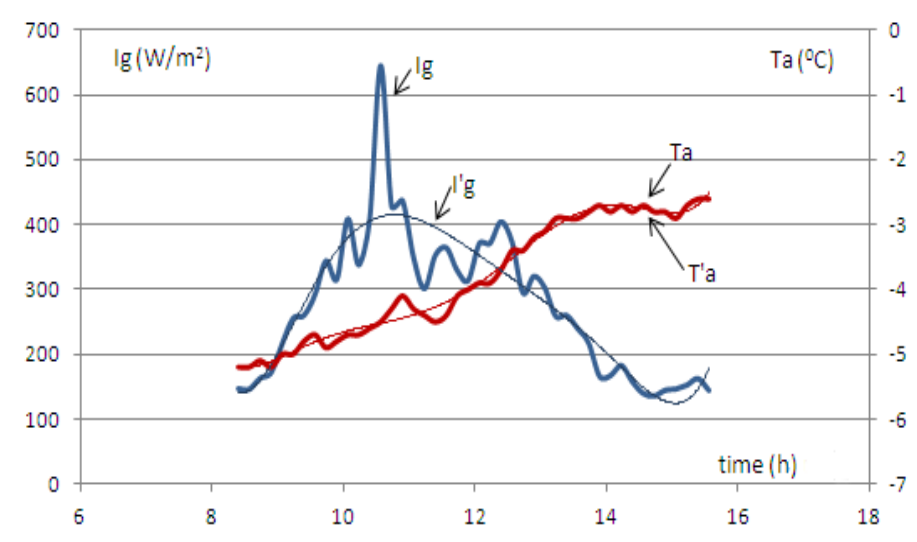

(a)

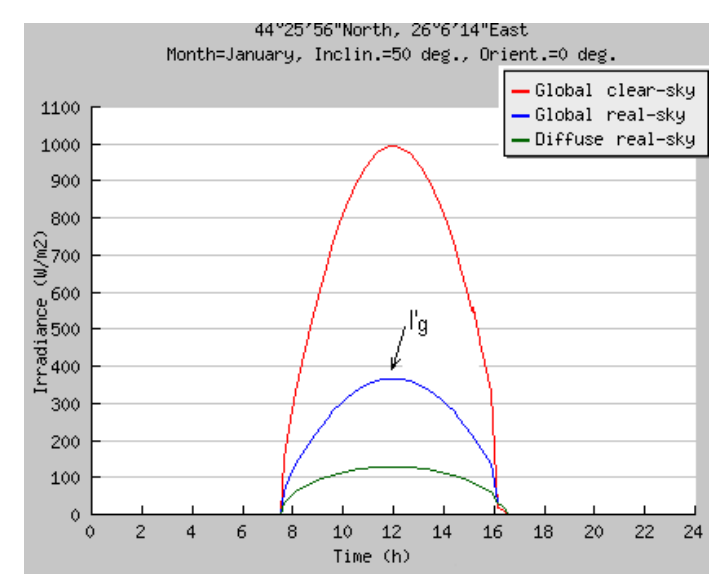

(b) 
Figure 2. Global solar irradiance on a tilted plane for a partly cloudy sky day from July, 2009: (a) Proprietary software, $T_{\mathrm{a}}$ and $I_{\mathrm{g}}$ are interpolated values with sixth degree polynomials; (b) JRC PVGIS application.

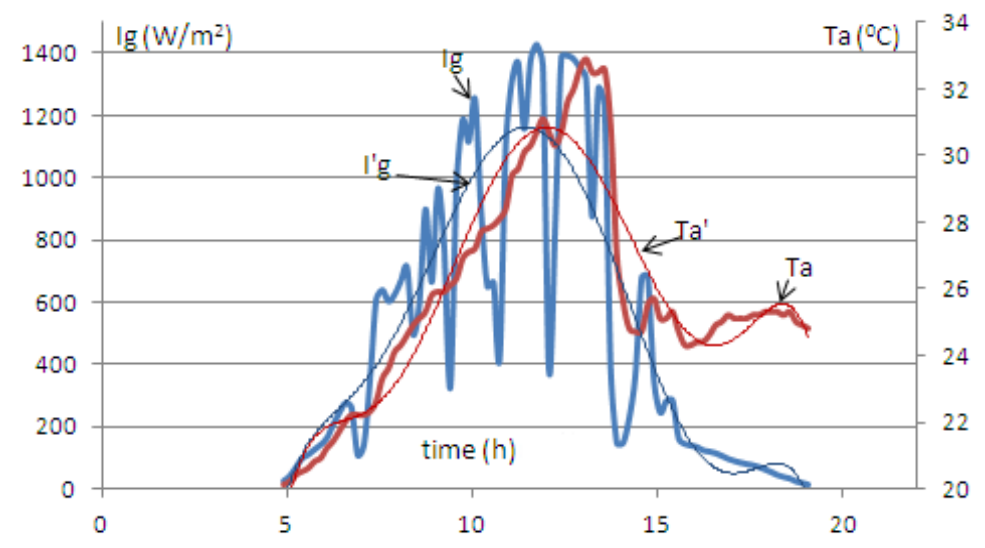

(a)

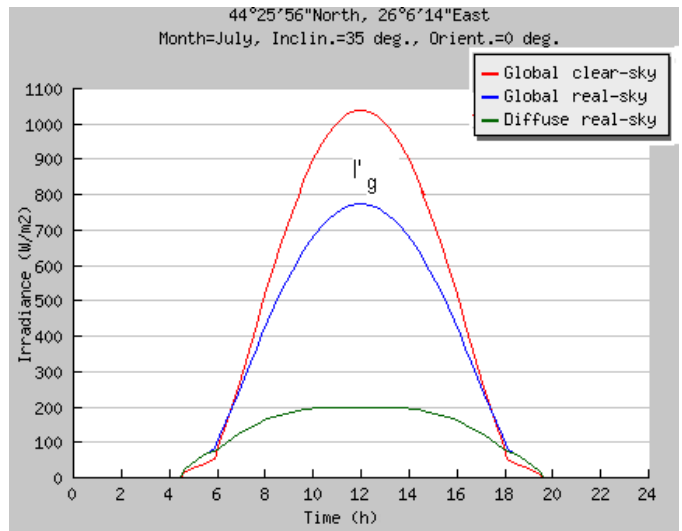

(b)

We measured the ambient temperature-inlet air temperature, the outlet temperature, the solar radiation, outlet air velocity, and the time intervals. For the heating process, the collector was exposed to the sun, for the cooling process the mobile stand was moved to the shade, with the fan continuously functioning.

The solar radiation was measured with a Voltcraft PL 110SM portable pyranometer (Conrad Electronic, Berlin, Germany), with accuracy $\pm 10 \mathrm{~W} / \mathrm{m}^{2}$, the temperature was measured with a laser thermometer Fluke 576 (Fluke Corporation, Everett, WA, USA) (accuracy $\pm 0.5^{\circ} \mathrm{C}$ ) and the air speed leaving the collector was measured with an anemometer (accuracy $\pm 3 \%$ ).

Figure 3. (a) Solar collector SH 1500, and system to modify the angle of inclination; (b) Optimal inclination angle for Bucharest [14].
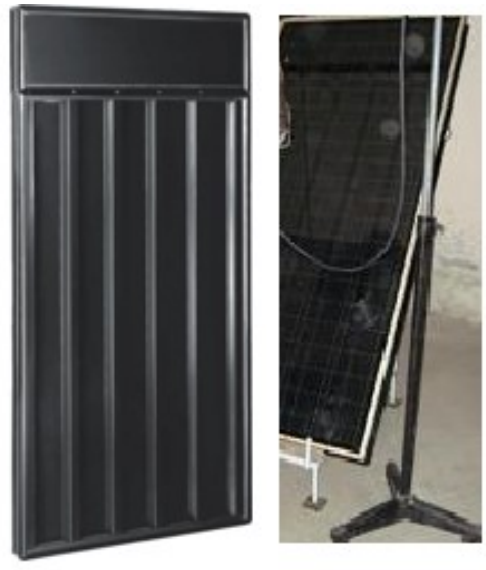

(a)

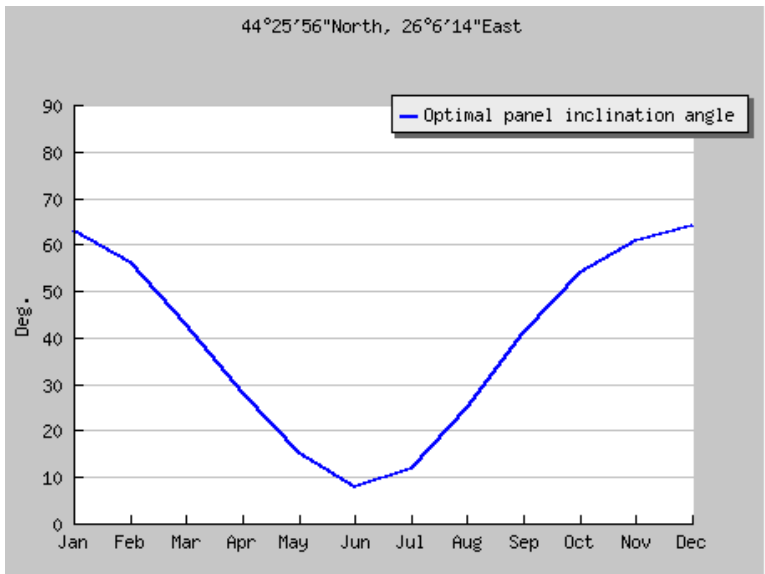

(b) 


\subsection{Mathematical Modeling}

In order to estimate the heat flux delivered by the solar air collector the following equation was applied:

$$
Q=c_{p} \cdot m \cdot \Delta T=c_{p} \cdot m \cdot\left(T_{\text {fout }}-T_{\text {fin }}\right)
$$

where $c_{p}=1008 \mathrm{~kJ} / \mathrm{kgK}$.

In Equation (1), $m$ is the mass flow rate in $(\mathrm{kg} / \mathrm{s})$, given by Equation (2):

$$
m=\rho \cdot l^{\cdot} \quad 4^{-2} \cdot v
$$

The efficiency of the solar collector was calculated with the following formula:

$$
\eta=\frac{Q}{I_{g}^{\prime} \cdot A_{c}}
$$

The atmospheric temperature, equal with the inlet air temperature, the outlet temperature, solar radiation, outlet air velocity, and the time intervals were measured. The heating characteristics of the collector, the air mass flow rate, the heat flux, the variation of the temperature, and, finally, the efficiency of conversion of solar energy into thermal energy, were calculated. For the cooling process the steps were the same, moving the collector to a shaded area, with the fan in operation.

\subsection{Results and Analysis}

The results were centralized in Figures 4 and 5: heat fluxes and outlet temperatures in the heating process (a), and in the cooling process (b), in July, and the same features on a day in January, Figure 5a,b. In addition, relationships between the solar global irradiation, the variation of temperatures, and outlet air velocity, were established, shown in Figure 6.

Figure 4. Heat fluxes and air outlet temperatures variation in times, in July: (a) heating process; (b) cooling process.

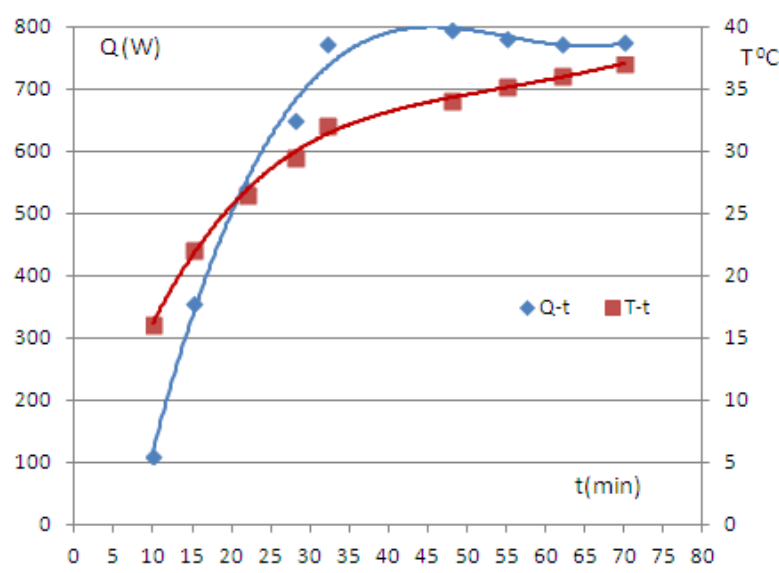

(a)

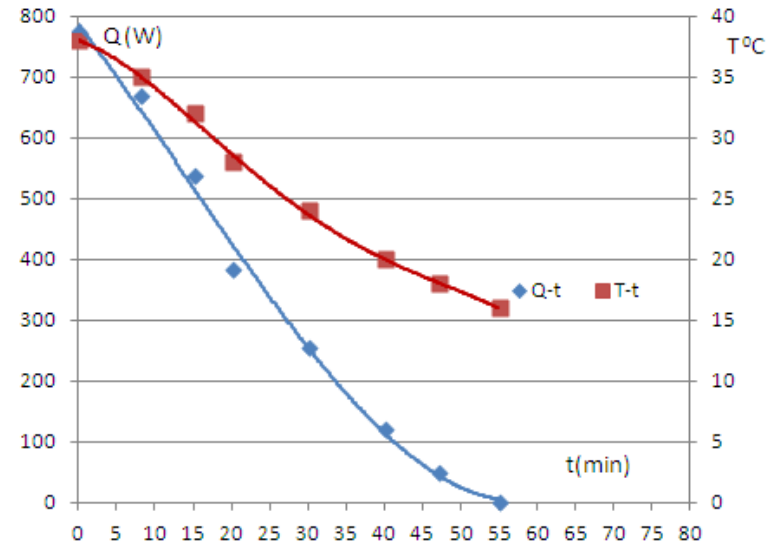

(b) 
Figure 5. Heat fluxes and air outlet temperatures variation in times, in a sunny day in January: (a) heating process; (b) cooling process.

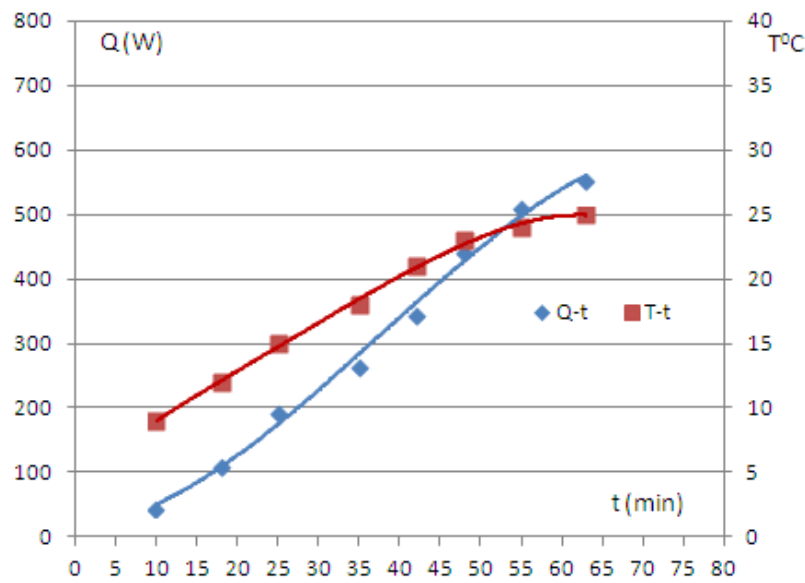

(a)

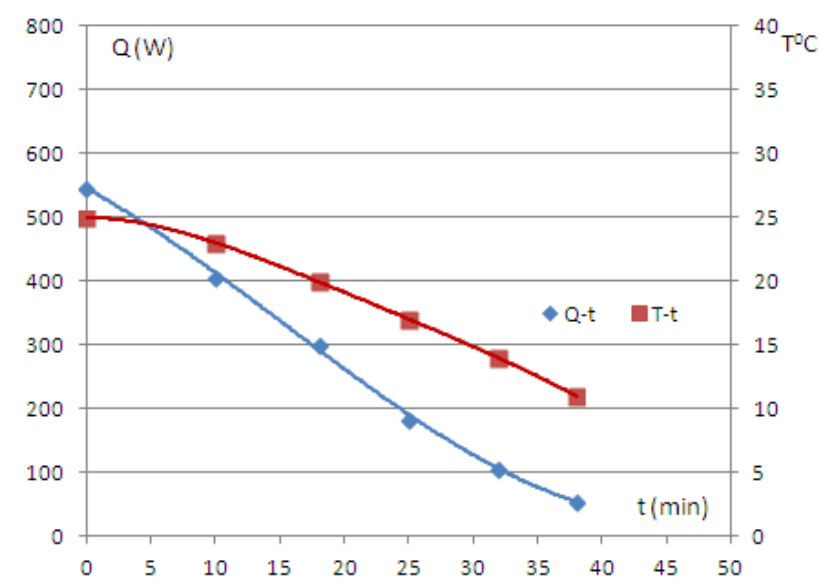

(b)

Figure 6. Solar global irradiance and the variation of temperature with air velocity.

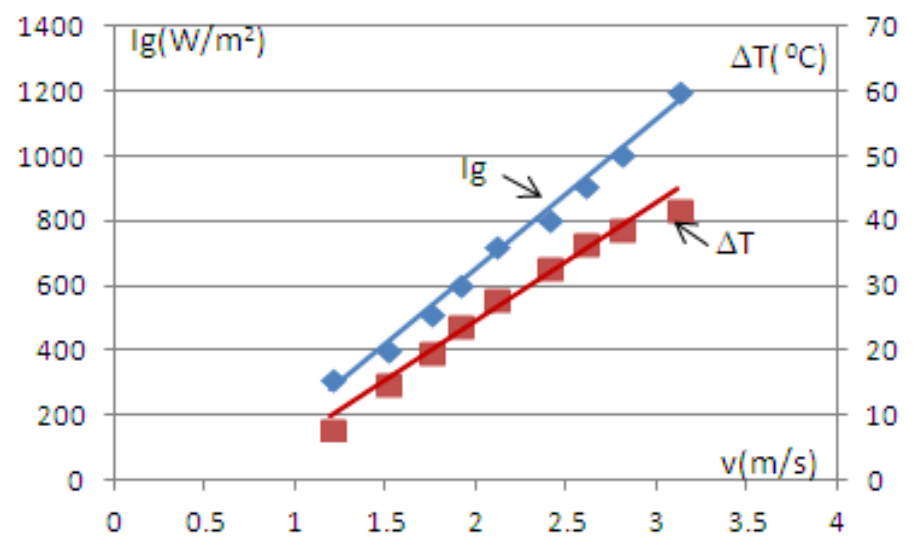

In the heating process, a stable functioning was found, representing the optimal operating point of the solar air collector, after about $50 \mathrm{~min}$ in summer, and $70 \mathrm{~min}$ in winter. In terms of cooling, it was done over a longer time in summer and in a shorter time in winter.

Figure 6 illustrates the increasing of the velocity of warm air, to the exit, from the collector, simultaneous with the increase of solar radiation, and the variation of air temperature, simultaneous with the decrease of the density of air.

The air velocity at the collector outlet could not be measured for solar radiation below $200 \mathrm{~W} / \mathrm{m}^{2}$ as the solar powered fan did not operate. From the mathematical point of view, a linear variation between $I_{g}$ and $v$, respectively, $\Delta T$ and $v$, of the form Equations (4) and (5), setting intersection with axes, can be found:

$$
\begin{gathered}
I_{g}=343.5 \cdot v \\
\Delta T=13.057 \cdot v
\end{gathered}
$$

Figure 7 illustrates the efficiency of the solar collector versus solar radiation $I_{g}$, and performance variation over time, to achieve the optimal operating point. From interpolation, Equation (6) is obtained, which can quickly determine the efficiency of the air collector when solar radiation is known: 


$$
\eta=-9 E^{-8} I_{g}^{3}+0.0001 I_{g}^{2}-0.0078 I_{g}
$$

Figure 7. Efficiency of solar air collector versus (a) solar radiation $I_{g}\left(\mathrm{~W} / \mathrm{m}^{2}\right)$ and (b) time $t$ (min).

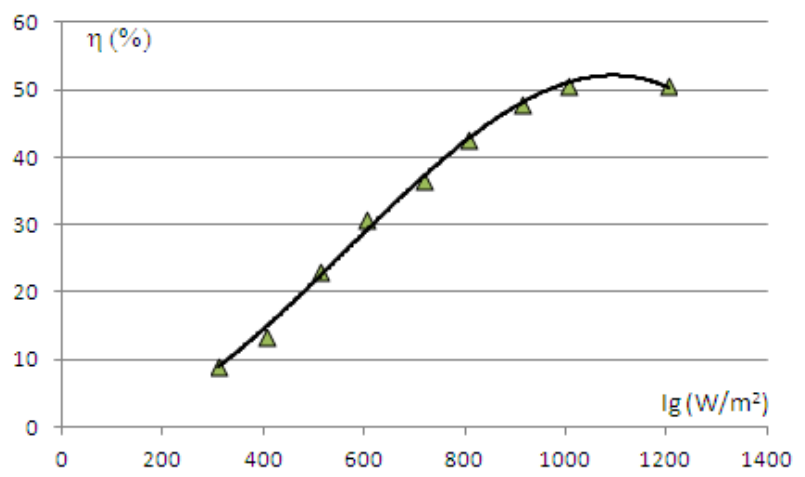

(a)

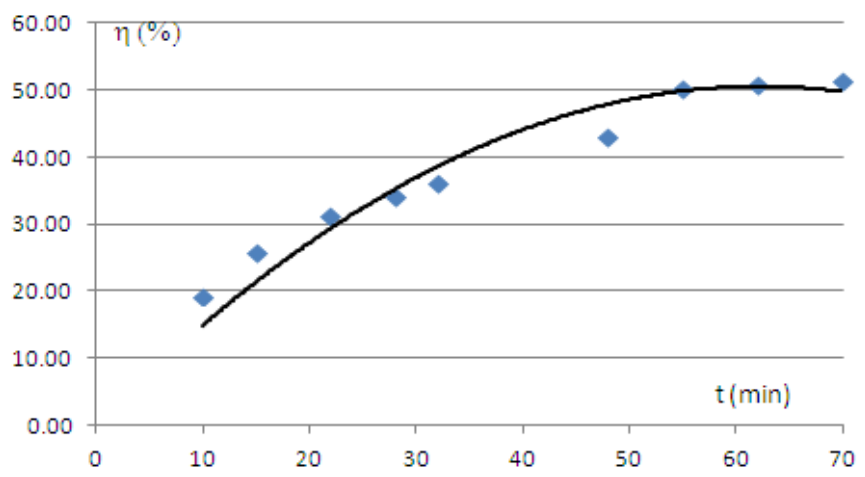

(b)

Similar results regarding efficiency were found by Morson [10]. The results are better than those presented by Visagavel [15], with 10\%-12\% due to the type of collector used in present experiments - double pass with baffles in galvanized aluminum. In Visagavel's experiments [15], a galvanized iron and single pass collector with a maximal efficiency of about $38 \%$ was used. In our experiments the collector eficiency is over $50 \%$ at the optimal operating point.

\section{Applications of Solar Collectors in Ventilation of Spaces}

Studies regarding building ventilation have important experimental components, both by combined chimney effects, also using solar air collectors [16-21].

\subsection{Computation Models for Natural Ventilation}

In summer, to evacuate the warm and polluted air from industrial or residential buildings, three computational models can be used to calculate natural ventilation: first, taking into account the internal thermal pressure, second, with the influence of external air currents, and, third, taking account of the heat transfer inside of solar collectors, located on the roof of the building.

Use of the solar air collectors is an efficient solution to induce supplementary natural ventilation. In this case, the mathematical model estimates the airflow rate through the tilted solar collector with a heat-absorbing material.

The main parameters are: the absorbing material and the glass surface temperature, the inlet and outlet air temperatures, the atmospheric temperature, the mass flow rate, the collector's surface, and the openings surfaces.

The mathematical model consists in thermal balance equations at the passing of the solar radiation through the glass cover, heat transfer to the air between the glass cover and the absorbing material, and through the channels of the absorbing material, in the following assumptions: laminar flow in the air channel; one-dimensional processes; the air inlet temperature is equal to the atmospheric temperature; and heat losses are neglected. 
Using Equations (4)-(6), for different values of solar radiation, the air velocity, the variation of temperature delivered by the collector, and its efficiency, can be obtained.

The equation for the energetic balance is:

$$
Q=\eta \cdot I_{g} \cdot A_{c}
$$

With heat flux:

$$
Q=A_{0} \cdot v \cdot \rho \cdot\left(T_{\text {fout }}-T_{\text {fin }}\right) \cdot c_{p}
$$

where $A_{0}$ is area of the outlet section $\left(\mathrm{m}^{2}\right)$.

Area of the solar collector is calculated, equaling Equations (7) and (8), and results:

$$
A_{c}=\frac{A_{0} \cdot v \cdot \rho \cdot\left(T_{\text {fout }}-T_{\text {fin }}\right) \cdot c_{p}}{\eta \cdot I_{g}}=l \cdot L
$$

By the increasing of $\Delta T$, the air's density decreases and results a new mass flow rate, from Equation (2) and a new heat flux, from Equation (1). With this heat flux, a new iteration is performed to obtain/to verify the final $A_{c}$ (Equation (7)).

\subsection{Case Studies}

As can be seen in the previous paragraph, for different global solar radiations $I_{g}$, air velocities $v$ and conversion efficiency values are different. For a family residence of about $200 \mathrm{~m}^{3}$ living space, the surface of the solar air collector results are as listed in Table 1.

Table 1. Area of solar air collector for three gradient of temperature, for a family house.

\begin{tabular}{ccccccccc}
\hline $\begin{array}{c}\boldsymbol{I}_{\boldsymbol{g}} \\
\left(\mathbf{W} / \mathbf{m}^{\mathbf{2}}\right)\end{array}$ & $\begin{array}{c}\boldsymbol{v} \\
(\mathbf{m} / \mathbf{s})\end{array}$ & $\begin{array}{c}\eta \\
(-)\end{array}$ & $\begin{array}{c}\Delta \boldsymbol{T} \\
\left({ }^{\circ} \mathbf{C}\right)\end{array}$ & $\begin{array}{c}\boldsymbol{A}_{\boldsymbol{c}} \\
\left(\mathbf{m}^{\mathbf{2}}\right)\end{array}$ & $\begin{array}{c}\Delta \boldsymbol{T} \\
\left({ }^{\circ} \mathbf{C}\right)\end{array}$ & $\begin{array}{c}\boldsymbol{A}_{\boldsymbol{c}} \\
\left(\mathbf{m}^{2}\right)\end{array}$ & $\begin{array}{c}\Delta \boldsymbol{T} \\
\left({ }^{\circ} \mathbf{C}\right)\end{array}$ & $\begin{array}{c}\boldsymbol{A}_{\boldsymbol{c}} \\
\left(\mathbf{m}^{2}\right)\end{array}$ \\
\hline 300 & 1.2 & 0.09 & 10 & 6.59 & 15 & 10.22 & 20 & 13.62 \\
400 & 1.5 & 0.15 & 10 & 3.7 & 15 & 5.75 & 20 & 7.66 \\
500 & 1.75 & 0.2 & 10 & 2.59 & 15 & 4.02 & 20 & 5.36 \\
600 & 1.85 & 0.28 & 10 & 1.56 & 15 & 2.43 & 20 & 3.41 \\
700 & 2 & 0.36 & 10 & 1.18 & 15 & 1.93 & 20 & 2.43 \\
800 & 2.4 & 0.42 & 10 & 1.06 & 15 & 1.64 & 20 & 2.19 \\
900 & 2.6 & 0.46 & 10 & 0.89 & 15 & 1.44 & 20 & 1.93 \\
1000 & 3 & 0.5 & 10 & 0.83 & 15 & 1.38 & 20 & 1.84 \\
\hline
\end{tabular}

Optimization strategies in solar collector operation involve the limitation of the exhaust air velocity to about $2.5 \mathrm{~m} / \mathrm{s}$. Limitation is imposed by the axial fan that works with photovoltaic energy. The graph in Figure 8 shows the variation of the useful area for solar collectors, used in improving the ventilation of the building, depending on solar radiation. The temperature variation $\Delta T=T_{\text {fout }}-T_{\text {fin }}$ in three cases, $10^{\circ} \mathrm{C}, 15^{\circ} \mathrm{C}$, and $20^{\circ} \mathrm{C}$, was considered.

The numerical results are summarized in Figure 8. As can be seen from the figure, for an average solar radiation of $500 \mathrm{~W} / \mathrm{m}^{2}$, ventilation of a house, of $200 \mathrm{~m}^{3}$, can be provided with about a $4 \mathrm{~m}^{2}$ collector area, which means two solar panels of the studied model. For radiation of $700 \mathrm{~W} / \mathrm{m}^{2}$ or better, a single air collector is sufficient. 
Figure 8. Area of solar air collectors versus solar radiation for three fields of temperature for a family house.

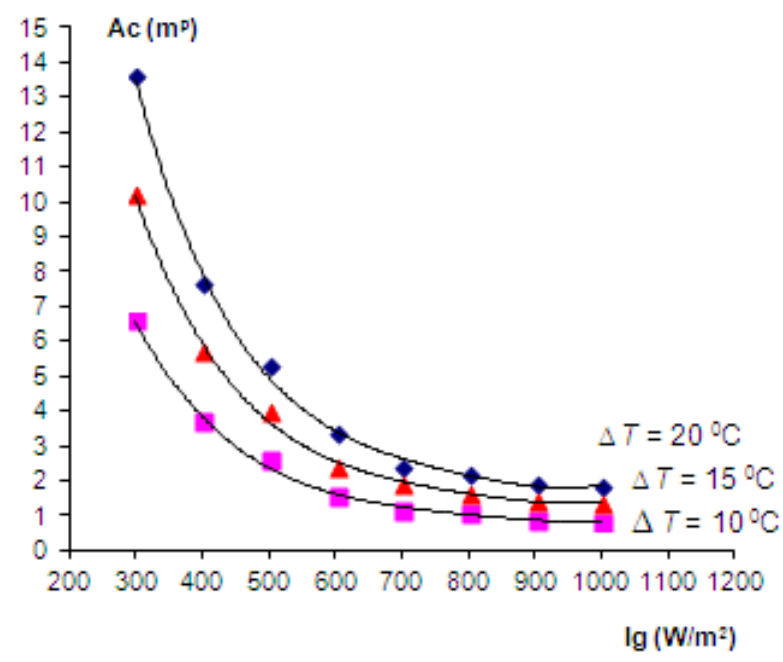

In Table 2, the same analysis is made for an office building, with about a $1000 \mathrm{~m}^{3}$ workspace, and results:

Table 2. Area of solar air collector for three gradient of temperature, for an office building.

\begin{tabular}{ccccccccc}
\hline $\begin{array}{c}\boldsymbol{I}_{\boldsymbol{g}} \\
\left(\mathbf{W} / \mathbf{m}^{\mathbf{2}}\right)\end{array}$ & $\begin{array}{c}\boldsymbol{V} \\
(\mathbf{m} / \mathbf{s})\end{array}$ & $\begin{array}{c}\boldsymbol{\eta} \\
\mathbf{( - )}\end{array}$ & $\begin{array}{c}\Delta \boldsymbol{T} \\
\left({ }^{\circ} \mathbf{C}\right)\end{array}$ & $\begin{array}{c}\boldsymbol{A}_{\boldsymbol{c}} \\
\left(\mathbf{m}^{\mathbf{2}}\right)\end{array}$ & $\begin{array}{c}\Delta \boldsymbol{T} \\
\left({ }^{\circ} \mathbf{C}\right)\end{array}$ & $\begin{array}{c}\boldsymbol{A}_{\boldsymbol{c}} \\
\left(\mathbf{m}^{\mathbf{2}}\right)\end{array}$ & $\begin{array}{c}\Delta \boldsymbol{T} \\
\left({ }^{\circ} \mathbf{C}\right)\end{array}$ & $\begin{array}{c}\boldsymbol{A}_{\boldsymbol{c}} \\
\left(\mathbf{m}^{\mathbf{2}}\right)\end{array}$ \\
\hline 300 & 1.2 & 0.09 & 10 & 32.95 & 15 & 51.1 & 20 & 68.1 \\
400 & 1.5 & 0.15 & 10 & 18.5 & 15 & 28.75 & 20 & 38.3 \\
500 & 1.75 & 0.2 & 10 & 12.95 & 15 & 20.1 & 20 & 26.8 \\
600 & 1.85 & 0.28 & 10 & 7.8 & 15 & 12.15 & 20 & 17.05 \\
700 & 2 & 0.36 & 10 & 5.9 & 15 & 9.65 & 20 & 12.15 \\
800 & 2.4 & 0.42 & 10 & 5.3 & 15 & 8.2 & 20 & 10.95 \\
900 & 2.6 & 0.46 & 10 & 4.45 & 15 & 7.2 & 20 & 9.65 \\
1000 & 3 & 0.5 & 10 & 4.15 & 15 & 6.9 & 20 & 9.2 \\
\hline
\end{tabular}

As can be seen in Figure 9, for radiation of $500 \mathrm{~W} / \mathrm{m}^{2}$, to achieve a difference of temperature of $10{ }^{\circ} \mathrm{C}$, a surface of $12 \mathrm{~m}^{2}$ is required, which means six solar collectors. For a variation of temperature of $20^{\circ} \mathrm{C}, 26 \mathrm{~m}^{2}$ are required, which means 13 solar air collectors, to improve natural ventilation.

By introducing the concept of air change per hour, $A C H$, as in Visagavel [15], given by Equation (9):

$$
A C H=\frac{\dot{V} \cdot 3600}{V_{r}}
$$

with $V_{r}\left(\mathrm{~m}^{3}\right)$ the volume of the room/ventilated space, values for $A C H$ were found, as in Table 3, compared to the values indicated by Mathur [20], Bassioiny [21] and Visagavel [15]. 
Figure 9. Area of solar air colectors versus solar radiation for three fields of temperature for an office building.

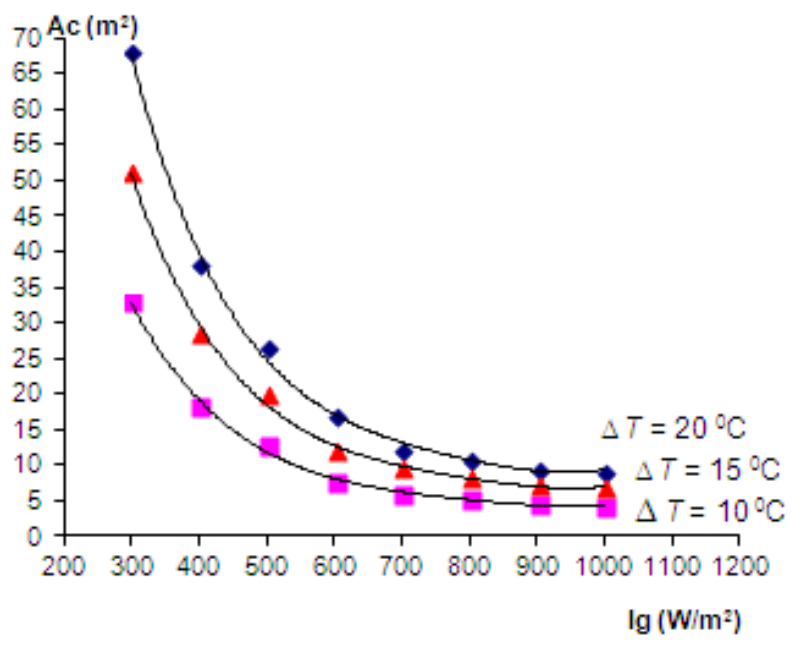

Table 3. Air change per hour $(A C H)$.

\begin{tabular}{ccccc}
\hline $\begin{array}{c}\text { Solar radiation } \\
\left(\mathbf{W} / \mathbf{m}^{\mathbf{2}}\right)\end{array}$ & $\begin{array}{c}\text { Mathur } \\
(\mathbf{2 0 0 6})[\mathbf{2 0}]\end{array}$ & $\begin{array}{c}\text { Bassiouny } \\
\mathbf{( 2 0 0 7 )}[\mathbf{2 1}]\end{array}$ & $\begin{array}{c}\text { Visagavel } \\
\mathbf{( 2 0 1 0 )}[\mathbf{1 5}]\end{array}$ & $\begin{array}{c}\text { Present } \\
\text { study }\end{array}$ \\
\hline 300 & 2 & 2.5 & 2.4 & 2.02 \\
500 & 2.2 & 3.2 & 2.6 & 2.9 \\
700 & 3 & 3.5 & 2.9 & 3.3 \\
\hline
\end{tabular}

\section{Conclusions}

The study of the energetic performance of solar heat collectors is important, both for their use in space heating, and also for natural ventilation systems integrated into building technology. The energetic building efficiency requires, on the one hand, better sealing and exhaust of polluted air, and, on the other hand, heating with solar energy, which is cheaper. Ventilation can be produced by forced ventilation, using fans and air cleaning equipment, by natural ventilation, where possible, or by mixed methods using solar air collectors.

The present paper offers experimental results and performances for a SH 1500G solar air collector, under Romanian climatic conditions, and proposes a method to improve the natural ventilation with these air collectors. The heating and cooling characteristics of the collector, the air mass flow rate, the heat flux, and the efficiency of solar energy conversion into thermal energy were determined.

This paper establishes relationships between the solar radiation, the air velocity and the variation of temperature, and also between $I_{g}$ and the efficiency of conversion of solar energy into thermal energy. The efficiency of this solar air collector is about $50 \%$.

The external wind velocity is difficult to incorporate into a technical model due to its random variations. This paper proposes a simplified method to measure the area to be covered with solar collectors to induce an air-flow rate, and to perform natural ventilation inside a building. Two case studies were realized to improve the ventilation with solar air collectors in a family residence of about $200 \mathrm{~m}^{3}$ living space, and for an office building of $1000 \mathrm{~m}^{3}$, by calculating the required area of solar collectors for three temperature gradients: $10{ }^{\circ} \mathrm{C}, 15{ }^{\circ} \mathrm{C}$, and $20{ }^{\circ} \mathrm{C}$. Finally, $A C H$ coefficient was determined and compared with values from similar papers. 


\section{Notation}

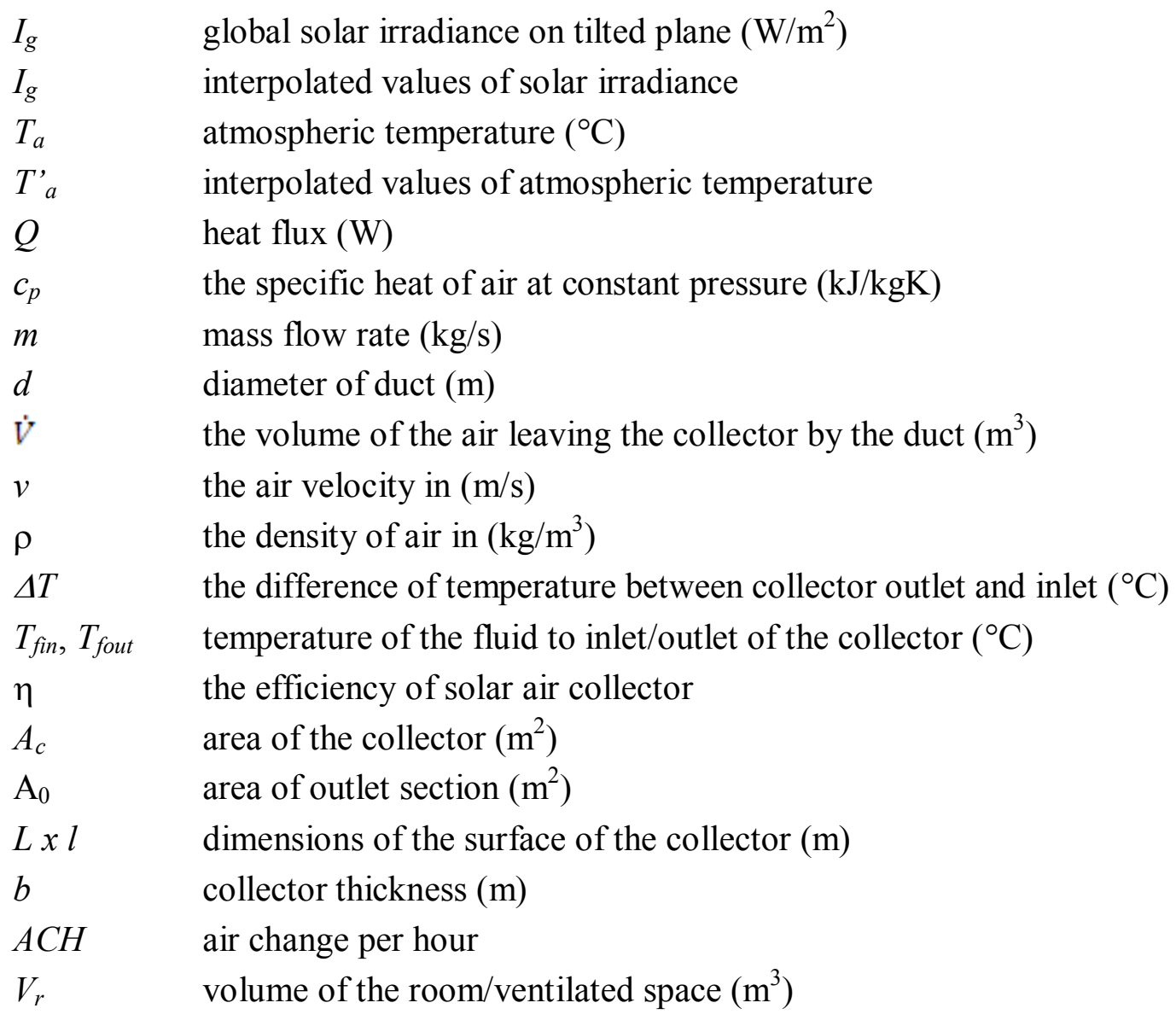

\section{Conflicts of Interest}

The author declares no conflict of interest.

\section{References}

1. Chiou, J.P.; El-Wakil, M.M.; Duke, J.A. A slit-and-expanded aluminum-foil matrix solar collectors. Solar Energy 1965, 9, 73-80.

2. Hachemi, A. Technical note comparative study on the thermal performances of solar air heater collectors with selective absorber plate. Renew. Energy 1999, 17, 103-112.

3. Biondi, P.; Cicala, L.; Farina, G. Performance analysis of solar air heaters of conventional design. Solar Energy 1988, 41, 101-107.

4. Gupta, D.; Solanki, S.C.; Saini, J.S. Heat and fluid flow in rectangular solar air heater ducts having transverse rib roughness on absorber plates. Solar Energy 1993, 51, 31-37.

5. El-Sawi, A.M.; Wifi, A.S.; Younan, M.Y.; Elsayed, E.A.; Basily, B.B. Application of folded sheet metal in flat bed solar air collectors. Appl. Therm. Eng. 2010, 30, 864-871.

6. Lanjewar, A.; Bhagoria, J.L.; Sarviya, R.M. Experimental study of augmented heat transfer and friction in solar air heater with different orientations of W-Rib roughness. Exp. Therm. Fluid Sci. 2011, 35, 986-995. 
7. Krzaczek, M.; Kowalczuk, Z. Thermal Barrier as a technique of indirect heating and cooling for residential buildings. Energy Build. 2011, 43, 823-837.

8. Chan, H.Y.; Riffat, S.B.; Zhu, J. Review of passive solar heating and cooling technologies. Renew. Sustain. Energy Rev. 2010, 14, 781-789.

9. Active solar air heating systems. Education of Architects in Solar Energy and Environment; Section 2.4, pp. 1-22. Available online: http://www-cenerg.ensmp.fr/ease/active_overheads.pdf (accessed on 10 February 2014).

10. Morson, I. Performance Review of the SH 1500 G Solar Air Heater; Ryerson University: Toronto, ON, Canada, 2007. Available online: http://www.yoursolarhome.com (accessed on 3 March 2012).

11. Ciocănea, A.; Dragomirescu, A.; Budea, S. Experimental research on transient regimes of solar air heat collectors. Environ. Eng. Manag. J. 2011, 10, 1097-1103.

12. Romdhane, B.S. The air solar collectors: Comparative study, introduction of baffles to favor the heat transfer. Solar Energy 2007, 81, 139-149.

13. Ramani, B.M.; Gupta, A.; Kumar, R. Performance of a double pass solar air collector. Solar Energy 2010, 84, 1929-1937.

14. JRC PVGIS. Available online: http://re.jrc.ec.europa.eu/pvgis/apps4/pvest.php?lang=en\&map=europe (accessed on 10 February 2014).

15. Visagavel, K.; Srinivasan, P.S.S. Experimental investigation on solar air heater assisted natural ventilation in single side ventilated room. Indian J. Sci. Technol. 2010, 3, 802-806.

16. Fraisse, G.; Johannes, K.; Trillat-Berdal, V.; Achard, G. The use of a heavy internal wall with a ventilated air gap to store solar energy and improve summer comfort in timber frame houses. Energy Build. 2006, 38, 293-302.

17. Zhai, X.Q.; Dai, Y.J.; Wang, R.Z. Comparison of heating and natural ventilation in a solar house induced by two roof solar collectors. Appl. Therm. Eng. 2005, 25, 741-757.

18. Hirunlabh, J.; Wachirapuwadon, S.; Pratinthong, N.; Khedari, J. New configurations of a roof solar collector maximizing natural ventilation. Build. Environ. 2001, 36, 383-391.

19. Sandberg, M.; Moshfegh, B. Ventilated-solar roof airflow and heat transfer investigation. Renew. Energy 1998, 15, 287-292.

20. Mathur, J.; Bansal, N.K.; Mathur, S.; Jain, M.; Anupma. Experimental investigations on solar chimney for room ventilation. Solar Energy 2006, 80, 927-935.

21. Bassiouny, R.; Nader, S.A. An analytical and numerical study of solar chimney use for room natural ventilation. Energy Build. 2007, 39, 128-135.

(C) 2014 by the authors; licensee MDPI, Basel, Switzerland. This article is an open access article distributed under the terms and conditions of the Creative Commons Attribution license (http://creativecommons.org/licenses/by/3.0/). 